\title{
The Science of Weights in Ancient Sri Lanka: A Study based on Equal Arm Balance from Alahana Pirivena, Polonnaruwa.
}

\author{
C. Jayawardana
}

\begin{abstract}
Early inscriptions as well as numerous literary sources refer to weight systems prevailed in ancient Sri Lanka. Supplementary to these sources, archeological excavations have revealed the remains of some early stage equal arm balances. The balance located during excavations at Menik Vehera of Alahana Monastic Complex, Polonnaruwa occupies a great importance among them due to its considerably preserved status. Intention of this paper is to link the details of weight systems as stipulated in the early textual sources with a sensitivity analysis on this ancient balance, exploring their correlation. In the mean time, findings of similar equal arm balances and alternative applications of different arm balances are also discussed. Limitations of weight as a measurement parameter and the application of volume for larger quantities such as grain measurements is also discussed, paving the way to identify the salient features of ancient weight system deviating from the present applications.
\end{abstract}

Key words: Weight Systems, Equal Arm Balance, Different Arm Balance, Sensitivity Calculation

\section{Introduction}

Weighing was among the earliest processes invented by man. Early societies used rudimentary measures such as seeds and stones as standard weights, against which the weight of other materials could be compared. When the weight of measurand is high, the volume or counting was often used, but adaptation of standard weights for moderate weights, goes back to pre Christian era. Cotterell \& Kaminga [1] summarizing some of the standard weights used in early civilizations note mina (equivalent of 489$680 \mathrm{~g}$ ), the standard weight used in Mesopotamia during 2400-600 BC. Egypt, as early as $2900 \mathrm{BC}$ possessed two standard weights sep (933g) and deban (93g). Roman Empire used standard weights talent $(26 \mathrm{~kg})$, librae $(327 \mathrm{~g})$ and unciae $(27 \mathrm{~g})$ while China, after 992 AD used dan (50kg) jin (500g) and liang $(50 \mathrm{~g})$. These information, lead us to conclude that apart from standardized weight system, a proper measurement systems also prevailed in these early societies.

\section{Weight measurements in Early Sri Lanka.}

The internal and external trading system, banking system, grants to various religious and social institutions, emoluments for employees, taxation, medicinal applications are some of the activities prevailed in ancient Sri Lanka, requiring a defined weighing system. However, scanning through the inscription details in early periods indicates only the lesser weights were measured using units of weight, while the higher weights were always measured through units of volume. Perera [2] and Codrington [3] referring to inscriptional evidence for weight measuring systems note, 1 . madadi (pillar inscription, Badulla), 2. aka (Mahinda IV slab inscription, Anuradhapura), 3. kalanda (Dappula IV slab inscription, Vessagiriya, $10^{\text {th }}$ century $\left.A D\right)$ and 4. huna (Council Chamber pillar inscription, Polonnaruwa) as units for early stage weight measurements, extensively used in the context of highly valuable items such as gold.

Codrington [4] examining the ancient texts including weight systems notes three such works, Abhidhanappadipika, Yogarnavaya and Vaidya Chintamani Bhaishadya Sangrahava. A detailed table of weights as given in the Abhidhanappadipika, text belongs to 12th century AD goes as,

Eng. C Jayawuardana [B.Sc (Eng)Hons, MTech, MA, MIET, MIE (Sri Lanka), C.Eng], presently

Project Manager, Cruickshanks Ceylon Pot. Ltd. Katunayaka. 


\begin{tabular}{|c|c|}
\hline 04 vee eta & $=01$ gunja \\
\hline 02 gunja & $=01$ mashaka \\
\hline $21 / 2$ mashaka & $=01 a k a$ \\
\hline $08 a k a$ & $=01$ dharana \\
\hline 05 darana & $=01$ suzanna \\
\hline 05 suvanna & $=01$ nikha \\
\hline 02 suramna & $=01$ pala \\
\hline 100 palas & $=01$ thula \\
\hline 20 thulas & $=01$ bhara \\
\hline
\end{tabular}

Literary works Yogamaonya and Vaidya Chintamani Bhaishadya Sangrahava belongs to Dambadeniya era (13 $3^{\text {th }}$ century AD) and Kotte era $\left(16^{\text {th }}\right.$ century AD) respectively, are consistent in specifying weight system,

03 thala eta $\quad=01$ amu eta

03 amu eta $\quad=01$ ree cta

08 vee eta $\quad=01$ madatiya eta

20 madatiya eta $\quad=01$ kalm

03 kalan =01 huna

04 huma $=01$ palam

The Saddhamarathanavaliya another literary work of the 13th Century AD presents the following table of measures,

03 amu eta $\quad=01$ vee cta

20 vee eta $\quad=01$ aka

08 aka $=01$ kalan or masu

It is evident that the similar system of measurements was continued to be used until the Kandyan era (17th century AD), as demonstrated by Knox [5]. Accordingly "....For their weights, there smallest is the Collanda, six make just a Piece of eight. They have half Collandas. When they are to weight things smaller than a Collanda, they weight them with a kind of red berries, which grow in the Woods, and are just like beads. The Goldsmiths use them. Twenty of these Beads make a Collanda, and twenty Collandas make a Pallum."

Codrington [4] and Davy [6], examining the samples of mavee seeds, a variety of paddy and madatiya (Adenanthera pavonina Linn) seeds from different places of the country concludes average weight per seed as 0.48 grains and 3.6 grains, an equivalent of $0.03 \mathrm{~g}$ and $0.24 \mathrm{~g}$ respectively. These relative measurements comply with the relationship between weights of vee etn and maditiyn eta as discussed above.
Coomaraswamy [7] noting the usage of madatiya by goldsmiths for weight measurements, equals the weight per seed to 3.6 grains, and conversion ratio between madatiy to kalanji (or manjadi) as 1:24.

As detailed above, weights as minute as $0.24 \mathrm{~g}$ were used as standard measurements from very early periods. In the study of ancient weighing systems in Sri Lanka, it is of utmost importance to examine the possibility of using balances with adequate sensitivity to accommodate weights of such range. Unfortunately, inscriptions and literary works refering to the types or technical features of the balances used to measure the specified weights are very rare, thus creating an unfilled gap between weight systems and their practical feasibility. In Saddharmarathnavaliya, reference is made to an equal arm balance, noting meritorious acts should be fulfilled while demolishing the sinful acts for the accomplishment of nirvana as a pan with less weight should be compensated from the pan with more weight. In same text, the arahat was equaled to a balance absorbing both disgrace and praise in equal manner. Despite such references, technical aspects of ancient balances are still to be explored, and it is in that context, analyzing measuring capabilities of ancient balance found at Alahana Pirivena archeological site, Polonnaruwa becomes significant in study of Sri Lankan engineering heritage.

\section{Ancient Balance at Alahana Pirivena.}

Alahana Pirivena, Polonnaruwa was a monastic complex, considered to be built by king Parakramabahu I (1153-1186 AD). Archeological explorations and excavations at this site were initiated by Central Culture Fund in 1981 and various types of religious buildings were identified such as image chambers [prathima ghara], Bo Tree shrines [bodhighara], dwelling quarters [arama] and hospitals [vejjashala] as well as artifacts like earthen ware, sculpture, metal kendi, etc, The small balance which is the key theme of this paper was found from south of Menik Vehera, the stupa belonged to Alahana Pirivena, was conserved and now in the display at Polonnaruwa Museum.

This is an equal arm balance, made out of copper alloy, having two pans and a cross beam with indicator. As currently stands, Ariyarathna [8] notes the dimensions as length 
of the beam, $13.9 \mathrm{~cm}$ and diameter of two pans, $7.4 \mathrm{~cm}$ and $7.5 \mathrm{~cm}$ respectively. Thickness of the pan is approximately $2 \mathrm{~mm}$. The entire contents were in state of corrosion at the time of unearthing, covered with oxide layer. At the time of unearthing, pans and cross beam were separated but two tiny holes at the ends of the cross beam and three holes at each pan indicate the plates were fixed to the beam ends by some means. Popular belief is that this was used for weighing medicine as a grinding stone also found from the same vicinity and also a similar balance was located from ancient hospital of Alahana Pirivena complex.

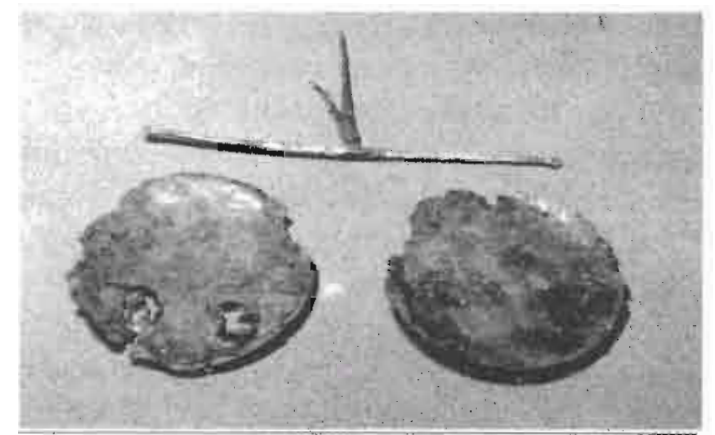

Fig. 1 Remains of balance from Menik Vehera site, Alahana Pirivena, Polonnaruwa

\section{Operating Mechanism and} Calculations.

Although the basic principle of equal arm balance is obvious, its stability needs some discussion. If a balance to be stable, its potential energy must be at a minimum when the beam is horizontal. Hence the centre of mass of the whole balance including pans, loads, weights, and beam, must be below the fulcrum point, $\mathrm{O}$ (fig. 2). However the centre of mass cannot be too far below the fulcrum as higher this distance, lower would be the sensitivity of the balance. 


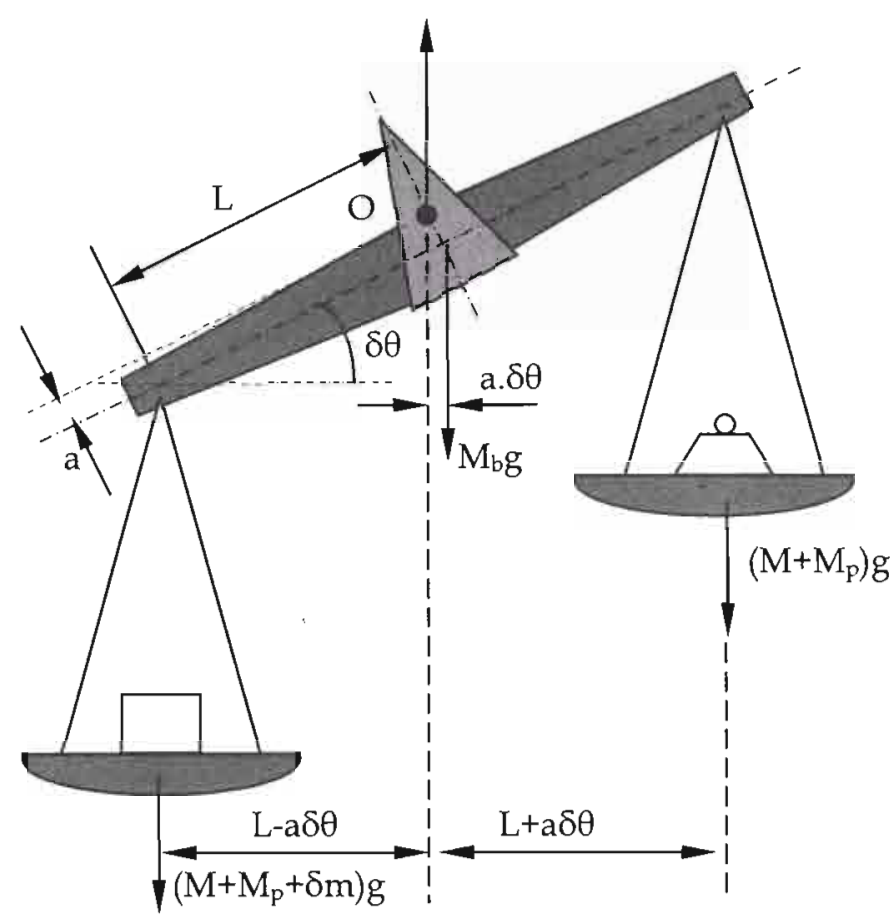

Fig. 2 Operating Principle of an Equal Arm Balance

The equilibrium state where one of the pans is a little heavier by $\delta m$ than the other, causing the beam to tilt through a small angle $\delta \theta$ is considered. For stability, the sum of all moments of the forces about the fulcrum ' $\mathrm{O}$ ' must be zero. If the angle $\delta \theta$ is small, the approximation $\sin (\delta \theta)=\delta \theta$ and $\cos (\delta \theta)=1$ could be used.

$\left(\mathrm{M}+\mathrm{M}_{\mathrm{p}}+\delta \mathrm{m}\right)(\mathrm{L}-\mathrm{a} . \delta \theta)=\left(\mathrm{M}+\mathrm{M}_{\mathrm{p}}\right)(\mathrm{L}+\mathrm{a} . \delta \theta)+$ $\mathrm{M}_{\mathrm{b}} \cdot \mathrm{a} . \delta \theta$ (1)

Where,

$\mathrm{M}=$ Nominal weight to be measured

$\mathrm{M}_{\mathrm{p}}=$ Weight of pan

$\mathrm{M}_{\mathrm{b}}=$ Weight of beam

$\mathrm{L}=$ Half length of the beam

$\mathrm{a}=$ Distance between fulcrum point and center of gravity of beam

Simplifying eqn. (1) and neglecting the second order quantity $\delta \mathrm{m} . \delta \theta$, $\delta \theta / \delta \mathrm{m}=\mathrm{L} / \mathrm{a}\left[2\left(\mathrm{M}+\mathrm{M}_{\mathrm{p}}\right)+\mathrm{M}_{\mathrm{b}}\right]$

(2)

which implies the increasing $L$ or decreasing $a$, $M, M_{p}$ and $M b$ increases the sensitivity of the balance. For practical applications,

$\mathrm{M}>\delta \mathrm{m}$

(3)

and, $\delta \mathrm{m}=\mathrm{nW}_{\mathrm{i}}$

Where,

$\mathrm{W}_{\mathrm{i}}=$ standard weight, $\mathrm{n}=$ positive integer

\section{Functionality}

A model as shown in fig. 3 was developed based on the data detailed by Ariyarathna [8]. The missing dimensions were assumed according to a scaled drawing, developed based on available dimensions. 


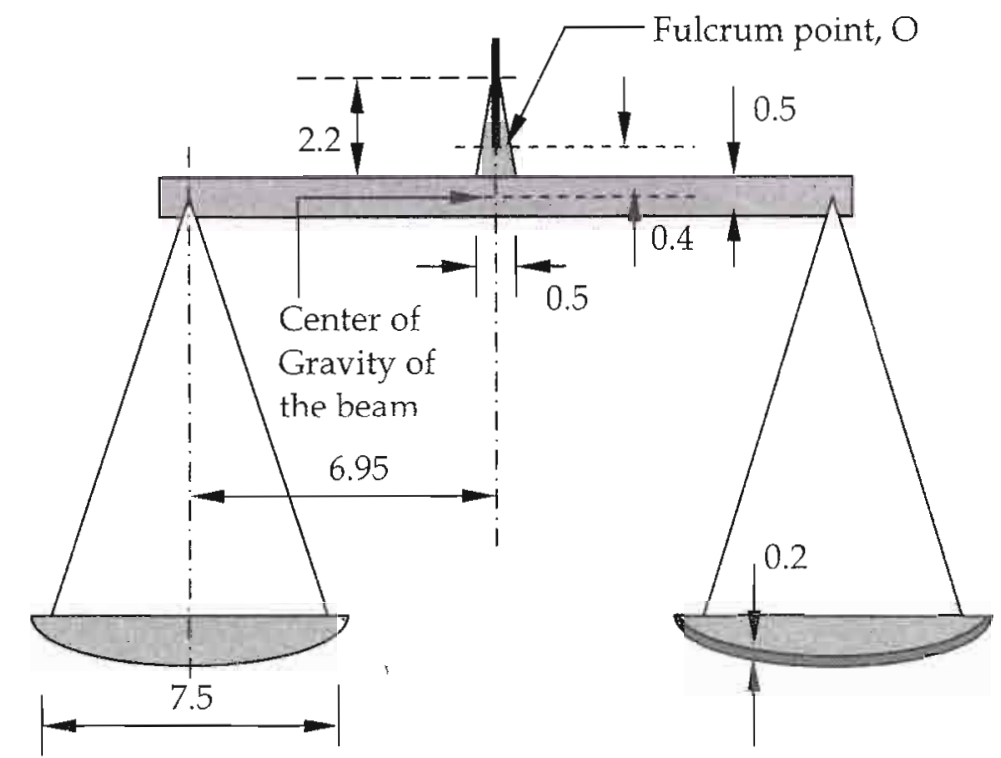

Fig 3 Hypothetical dimensions of balance

Based on the dimensions thus obtained and the density of the material assumed as that of brass $8.73 \mathrm{gcm}^{-3}$, the following values were obtained.

Metal volume of the beam and indicator $=$ $2.89 \mathrm{~cm}^{3}$

Metal mass of the beam and indicator, $\mathrm{M}_{\mathrm{b}}=$ $25.27 \mathrm{~g}$

Metal volume of a pan $=8.61 \mathrm{~cm}^{3}$

Metal mass of a pan, $M_{p}=75.12 \mathrm{~g}$

Horizontal distance between fulcrum and pan fixing point, $\mathrm{L}=6.95 \mathrm{~cm}$

Vertical distance between fulcrum and beam centre of gravity, $\mathrm{a}=0.4 \mathrm{~cm}$

As sensitivity $\delta \theta / \delta \mathrm{m}$ is a function of $M$, the nominal weight to be measured, an absolute value for $\delta \theta / \delta \mathrm{m}$ could not be reached. Criteria used for evaluating the sensitivity is,

(1) The observable tilt of the beam was assumed to be $3^{0}$ deg., thus minimum measurable weight difference, $\delta m_{\min }$ is the weight difference producing such tilt.

(2) $\delta \theta$ was calculated for a range of $\delta \mathrm{m}$, for different $M$ values. The $\delta \mathrm{m}$ range thus selected was from 1 to 8 vee eta and 1 to 20 madatiya eta as Table 1.

(3) Graphs were developed for above (2) and $M>\delta m, \delta \theta>3^{0} \mathrm{deg}$, as fig. 4 .

(4) $\delta m_{\min }$ was calculated for each $M$, so that the minimum weight measurable from this balance could be determined.

Table 1 Tilt angle, $\delta \theta$ for Weight differences, $\delta \mathrm{m}$, under different measurands, $M$

\begin{tabular}{|c|c|c|c|c|c|c|c|c|}
\hline \multirow{2}{*}{$\begin{array}{l}\text { Weight diff. } \\
\text { om in } \\
\text { standard units }\end{array}$} & \multirow[b]{2}{*}{$\begin{array}{l}\text { Equivalent } \\
\text { Weight, g }\end{array}$} & \multicolumn{7}{|c|}{ Tilt angle, $\delta \theta^{\circ} \mathrm{deg}$. } \\
\hline & & $\begin{array}{c}\mathrm{M}=4 \\
\text { vee }\end{array}$ & $\begin{array}{c}\mathrm{M}=8 \\
\text { vee }\end{array}$ & $\begin{array}{c}\mathrm{M}=2 \\
\text { madati }\end{array}$ & $\begin{array}{c}\mathrm{M}=5 \\
\text { madati }\end{array}$ & $\begin{array}{l}\mathrm{M}=10 \\
\text { madati }\end{array}$ & $\begin{array}{l}\mathrm{M}=15 \\
\text { madati }\end{array}$ & $\begin{array}{l}\mathrm{M}=20 \\
\text { madati }\end{array}$ \\
\hline 2 ree eta & 0.06 & 0.59 & 0.59 & 0.59 & 0.59 & 0.57 & 0.55 & 0.54 \\
\hline 4 vee eta & 0.12 & 1.19 & 1.18 & 1.18 & 1.19 & 1.14 & 1.11 & 1.09 \\
\hline 6 vee eta & 0.18 & & 1.78 & 1.77 & 1.78 & 1.70 & 1.66 & 1.63 \\
\hline 8 vee eta & 0.24 & & 2.37 & 2.36 & 2.37 & 2.27 & 2.22 & 2.17 \\
\hline 2 madatiya & 0.48 & & & 4.71 & 4.75 & 4.54 & 4.44 & 4.34 \\
\hline 3 madatiya & 0.72 & & & & 7.12 & 6.81 & 6.66 & 6.51 \\
\hline 4 madatiya & 0.96 & & & & 9.49 & 9.08 & 8.88 & 8.69 \\
\hline 5 madatiya & 1.2 & & & & 11.87 & 11.35 & 11.10 & 10.86 \\
\hline 6 madatiya & 1.44 & & & & & 13.62 & 13.32 & 13.03 \\
\hline
\end{tabular}




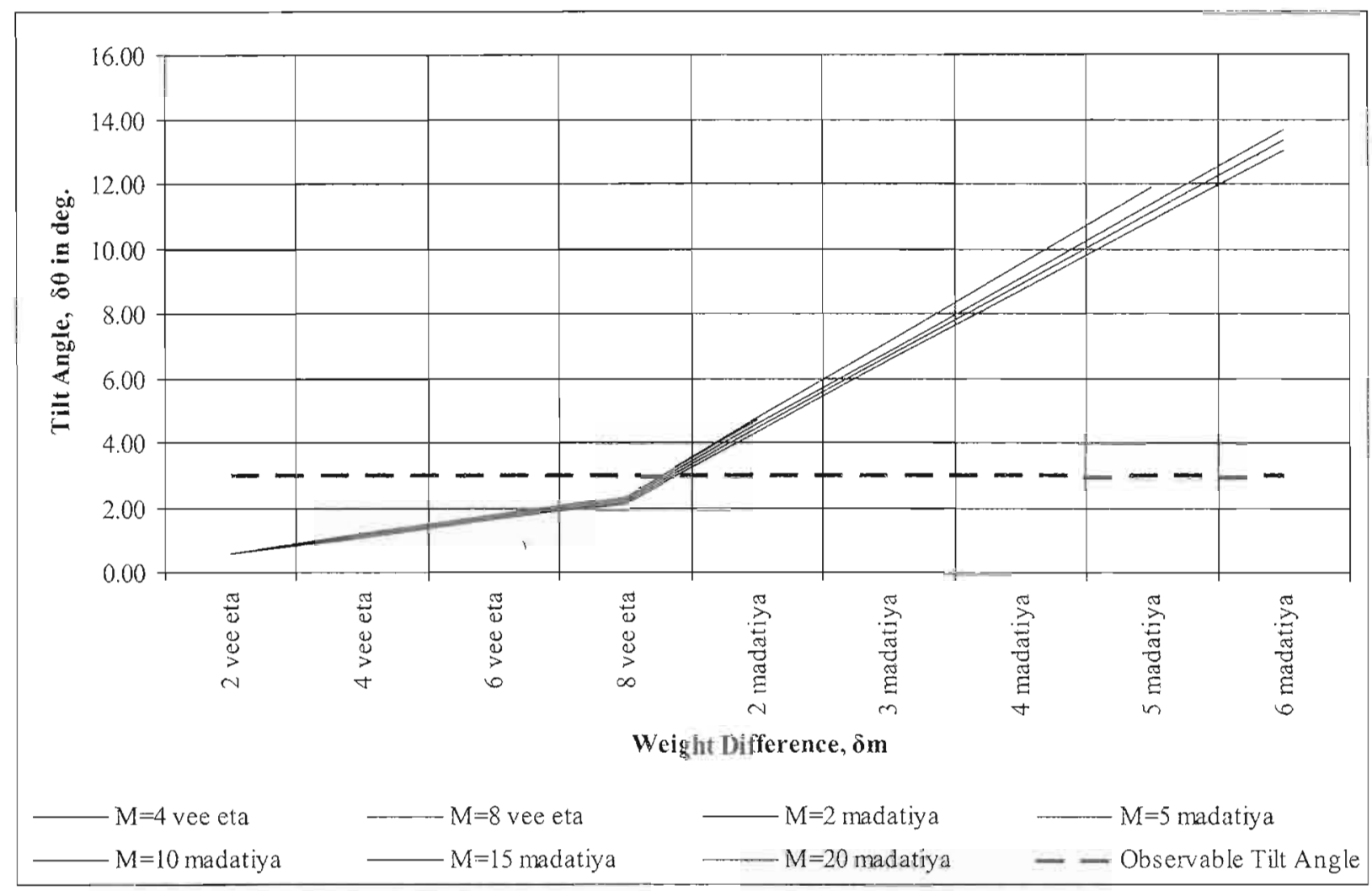

Fig 4 Tilt angle for Weight differences

From fig. 4, it is evident that for all practical purposes, the tilt angle is not depending on $\mathrm{M}$, introducing a high variance of accuracy in measurements. Observable tilt angle, i.e $3^{0} \mathrm{deg}$. is introduced by $\delta m_{\min }$ of 2 madatiya, implying that the weight difference between the measurand and standard weight should be more than 2 madatiya, in order to observe any such weight difference. The tolerance at weight of 2 and 20 madatiya is $100 \%$ and $10 \%$ respectively. This balance could not be used for measurements for weight differences below 2 madatiya, i.e. standard weights like thala, amu or vee could not be used in the context of this balance.

\section{Similar Ancient Balances}

Apart from the balance discussed above, another similar balance was found from the ancient hospital site from the Alahana Pirivena Complex. No exact dimensions are available to the author, hence the functionality could not be ascertained. Construction features are similar to the balance under discussion.

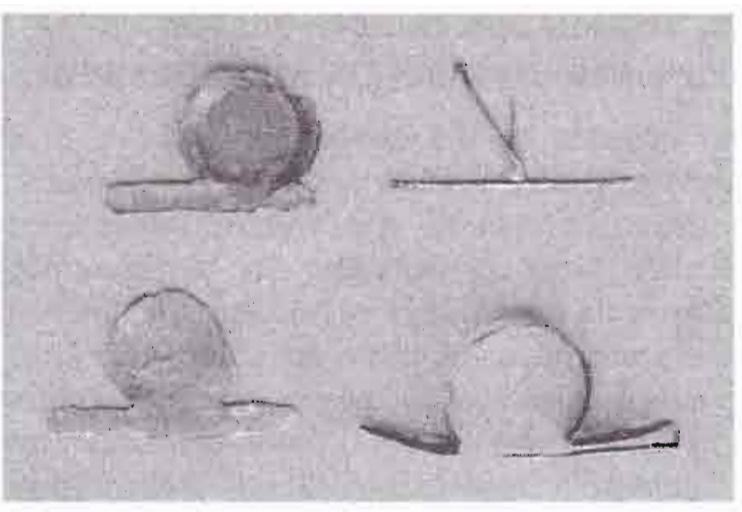

Fig. 5 Remains of balance from Hospital site, Alahana Pirivena, Polonnaruwa

A very delicate balance made out of ivory is also in the display at Colombo National Museum, Kandy Period Gallery. This is dated back to the reign of king Rajasimha I (15811892 AD), and cross beam is decorated with extremely delicate carvings, reducing it weight $\left(M_{b}\right)$ as well as the structural strength. A special container dedicated to the safe keeping of the balance is also displayed in same location.

\section{Different Arm Balance}


An extra ordinary balance is currently in display at Rathnapura museum. This is consisting of a tapered shaped wooden pole, to which a pan is fixed through ropes at the smaller edge. Fulcrum point is just after this pan fixing point, making the rest of the pole is acting as lever against the measured weight. As no calibrations provided, the balance could only be used for a unique measurement, of which value should be predetermined. The time of construction or usage could not be reliably sourced.

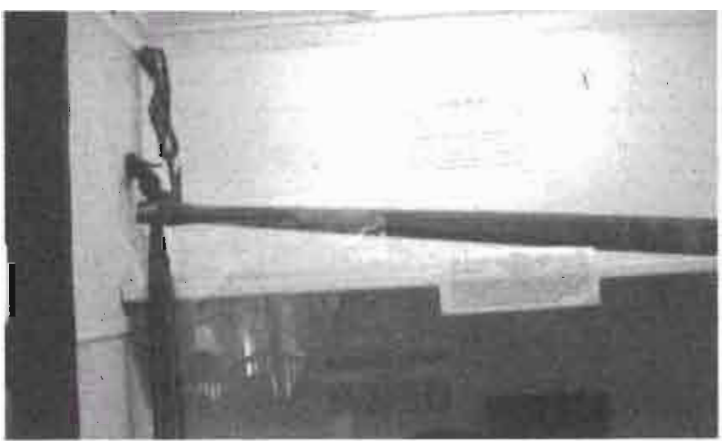

Fig. 6 Remains of non-equal arm balance displayed at Rathnapura museum

\section{Volume as a Supplementary Parameter for Weight Measurements.}

In contrast to the above applications, it is evident from the early periods that volumetric measures replaced the weight system for higher range of weights. For an example, Thonigala inscription regulating the interest for grain deposits, refers to volumetric units sakata and amuna, as measuring units. Perera [2] and Codrington [4] note the units for volumetric measurements in inscriptional evidence as 1. yahala, 2. amuna, 3. pala (or pekada or peyala), 4. lahasu (slab inscription, Rambawa), 5. nali (slab tablets, Mihintale), 6. adamana (slab tablets, Mihintale) and 7. pata (slab inscription, Eppawala)

Pieris [9], referring to the work of Hartshorne [10] notes a system of weights in existence during Kandy period $\left(17^{\text {th }}-18^{\text {th }}\right.$ century $\left.A D\right)$.

$\begin{array}{ll}03 \text { thala eta } & =01 \text { amu eta } \\ 03 \text { amu eta } & =01 \text { vee eta } \\ 03 \text { vee eta } & =01 \text { madatiya } \\ 10 \text { madatiya } & =01 \text { kalanda } \\ 03 \text { kalan } & =01 \text { huna } \\ 02 \text { huna } & =01 \text { palam } \\ 02 \text { palam } & =01 \text { kuludul } \\ 01 \text { kuludul } & =01 \text { patha } \\ 02 \text { patha } & =01 \text { mana } \\ 02 \text { mana } & =01 \text { neli }\end{array}$

$21 / 4,3,31 / 2$ or 4 neli $=01$ las

10 las $\quad=01 \mathrm{pal}$

04 pal $=01$ amunu

Evidently, volume has been used for measuring higher weights, and equivalence between weight and volume has been established through the link palam and patha. Such conversion could only be interpreted in the terms of density of the material and the general conversion table as above presents inconsistent data, deficient in present day context.

\section{Conclusion.}

Based on the above revealings, some basic features of ancient Sri Lankan weighing system could be identified. The metallurgy and craftsmanship prevailed by $12^{\text {th }}$ century $\mathrm{AD}$ enabled the manufacturing of balances, having a measuring capability ranging from the weight of 2 madatiya seeds, i.e. $0.48 \mathrm{~g}$ upwards. The results received from the calculation supplement the textual fact that madatiya seeds were used in early Sri Lankan weight systems. The usage of standard weights with lesser values should be supported by more sensitive balances, which may be fulfilled by the ivory balance discussed above, but could not be proven in the absence of required data.

Even though sources refer to several standardized units systems, their conversion tables are not consistent, giving the impression of informality. This may be extended to the common feature of limited applicability, possessed by our ancient technologies. No units for higher weights were developed and grain measurements for all practical purposes were through volumetric measurement. The accuracy of such system may vary in a wide range. Considering a measurement such as sakata [meaning a cart load] used for grain measurement for investment purposes means the accuracy of the quantitative measurement of grains was of less concern. This should not be interpreted as a lack of technical know how for accurate weight measurements. If technical competency prevailed enough to produce a balance with accuracy under the discussion, weight measurement of high order would not have been a technical hindrance. The underlying reason may be well rooted in social and cultural perspectives, which calls for further investigation on such factors transcending the technical feasibilities. 


\section{References}

[1] Cotterell, B., \& Kaminga, J., Mechanics of Pre Industrial Technology, University of Cambridge, U.K., 1990

[2] Perera, L.S., The Institutions of Ancient Ceylon from Inscriptions (from 831 to 1016 AD), Vol. II, Part II, International Center for Ethnic Studies, Kandy, Sri Lanka, 2005

[3] Codrington, H. W., Ceylon Coins and Currency, Memories of Colombo Museum Series A, No. 3, Colombo, 1924.

[4] Codrington, H. W., Ancient Land Tenure and Revenue in Ceylon, Department of Education Publications, Colombo, 1980.
[5] Knox, R., An Historical Relation of Ceylon, 4th Edition, Thisata Prakashakayo Ltd., Dehiwala, 2006

[6] Davy, Interiors of Ceylon, Colombo, 1821.

[7] Coomaraswany, A. K., Medieval Sinhalese Art, 3rd Edition, reprinted in State Printing Corporation, Sri Lanka, 1979

[8] Ariyatathna, R. G., Menik vehera puravidhya sankecranayen hamuwu thamba misritha loha tharadiya sanrakshanya kireema, Nisshanka, Vol. I, Issue I, Polonnaruwa Project, Central Cultural Fund, 2000

[9] Pieris, R. E., Sinhala Sanajaya, translated by K.A.D. Perera, Visidunu Prakashakayo, Boralesgamuwa, 2001.

[10] Hartshorne, B. F., Administration Report on the Nuwara Eliya District, Ceylon Government, 1872. 